\title{
Organizing of Physical Education Teaching Classes and Methods to be Used to Achieve the Intended Objectives
}

\author{
Rovena Elmazi \\ Ledina Koci \\ rd.elmazi@gmail.com
}

\author{
Doi:10.5901/jesr.2015.v5n1s1p97
}

\begin{abstract}
Physical education is an integral part of the comprehensive education of pupils. It represents the whole of the methods that aim to improve the psycho-motor qualities of them. Physical education and education are closely related to each other. Encouraging and promoting children to work with desire and seriously begin since preschool age and later at school. For this reason in the content of the preschool cycle program, different games should prevail, led by the teacher who seek not only fun but also develop pupils' motor skills. Physical education teachers have an important role in this development process. They must commit to implementing the program quality, well recognize how its content should be performed, the load to be taken and in particular anatomic physiological progress, the psyche progress and the motor progress that delivers every motor activity conducted within the classroom. Physical education teacher in his work looks to each student's level of motor skills formation as one of the basic requirements contained in the program. He must identify the anthropometric indicators, physical attributes and motor skills of the students and on the basis of these indicators will organize and differentiated work. First of all differential work is strongly supported in the motor skills level, to continue with the advanced elements by adapting the physical possibilities of the pupils. Teachers must have a special attention to the terminology used in order to be as clear and comprehensible his instructions to them.
\end{abstract}

Keywords: Physical Education, program, method, terminology, psycho-motor qualities, motile

\section{Introduction}

The academic teaching process of physical education applies general didactic principles which apply to other subjects as well including systematic learning, learning adaptation based on mental and physical capacity and student-developed classes. Learning in the process of physical education has a significant educational nature especially from the social aspect. Consequently, the teacher must not separate the acquisition of movements, development of physical qualities, anthropometrical qualities and agility from education of moral and ethical values of the students. Any didactic analysis of physical education must be anticipated by the structural analysis and physical and sports exercise which inter alia consists in the study of the elementary movements, substance of the physical exercises and their learning. Moreover, it would be more important to know the position of physical education in the school.

\section{Aim of Study/Research}

The aim of this study is to become acquainted with the teaching methods in the physical education classes and select the proper methods for organisation of the teaching classes in order to achieve the intended objectives. Throughout my experience as a teacher of physical education I have concluded that the choice of the proper method plays a very important role in the quality of the classes. The methods consist in the set of means and way of teaching based on which the student, under the guidance of the teacher try to acquire knowledge, agility, movement expression on the one side and attain the objective of their education in general on the other side. There are three methods to organise physical education classes: 1- demonstration method, 2- verbal method and 3- exercise method. Such methods must be selected by the teacher based on the age, knowledge of the students about the topics and their physical skills. Each of the methods has its own specifics. 


\section{Research Topic}

The reason for this research is built upon the mission we have to forward the message that sports is the key to the psycho-motor development of the children. As a teacher of physical education, I have come to the conclusion that the better the organisation of the classes by the teacher, the better are the results of the development of the students. It is to this end that we decided to make this research to show that the method chosen to transmit knowledge to the student is the most important step which must never be undermined.

\section{Research Question}

The main research question is: what is the proper method to be used during the physical education classes in order to attain the required objectives? Before elaborating on this question, first we must know which are the methods and their specifics, and whether they are closely linked to the age-group of students. Such questions shall be answered in the following sections.

\section{Scientific Methods}

The methods used for this study are examination of the students in public and non-public schools in Tirana during the physical education classes. It all started with the children of the pre-school system and depending on the topic of the day we have used three methods to conclude which is the most relevant method to make the topic easily understood and applied. We applied the same method to the students starting from the first to the fifth grade. Concerning the students of the sixth to the ninth grade we initially tested their theoretical knowledge on the subject and then we used the methods and concluded on the most appropriate method to have qualitative teaching and learning classes.

\section{Discussion}

The physical education subject and participation in various sports activities plays a very important role in the psychomotor development. The school must not transmit knowledge alone. In addition it must affect the education of their skills. Children, before going to school, learn with all their senses and improve quickly their mistakes, therefore learning at a clearly defined pace very often seems tiring wearisome. If we want children to be more motivated for this teaching class, we must clearly explain them why it is necessary to attend the physical education classes and their usefulness. Employing various games, especially those in the form of races through which the students experience positive emotions, is essential in feeding their motivation for the physical education class.

Physical education is integral part of their comprehensive education. It constitutes the set of methods which aim at improving the psycho-motor skills of students. It has to be reemphasised to the students of the elementary cycle that they must be able to run, swim, be disciplined, persistent, daring, qualities which help them grow strong. To this end, special attention must be paid to this area, especially during the work of the physical education teachers. In their capacity, they must work with both seriousness and will.

In order to succeed in their work, the teachers must be willing and devoted in implementing the academic programme, which aims at the psycho -motor development of the children. It consists of several movement activities which are performed successfully through the better organisation of students during the teaching classes and proper use of methods in order to make it as simple and understandable for the student.

It is up to the teacher to prepare, before organising the classes, the place where the class will be delivered and use the means to the employed for the topic in question. The forms of organising the classes must guarantee effectiveness in the ability to acquire movement expressions. The teacher must be cautious in the choice of terminology, which must be clear and simple, so as to be as understandable as possible by the student.

The methods of delivery of classes consist in the set of methods used by the teachers during the classes in order to make the exercise as clear to the student. The use of one method or the other depends on the skills of the teacher, the content of the teaching classes, the individual features of the students, materials etc. They are not rigid but they are adapted to the topic of the teaching classes very often and referring to the absorption by the student, the methods of the physical education are divided in the three main groups:

1- Demonstration method

Demonstration must present the technique of movements in a perfect and dynamic manner. The teacher explains 
the exercise, demonstrates the exercise and shows it in slow motion indicating in this way the steps to be followed by the student in performing the exercise. If the teacher because of physical reasons is unable to demonstrate the exercise, it is better to assign two or three students whose movement skills are the best.

\section{2- Verbal method}

The use of this method depends on the age of the student, because the older they are easier and fruitful this method is. In this case, terminology of the teacher must be laconic, fluent and adapted to the level of the students. In the use of this method, the main issue is the explanation which requires systematic presentation of knowledge of technique of exercises and the manner of performing the exercises. An example is the topic "chest pass". In this case the teacher explains the position of the body, stepping towards your target with one foot, then throwing the ball out towards the chest with two hands while turning the hands over, ending with the thumbs pointing down. etc.

\section{3- Exercise method}

It is an independent method used widely in the learning of movement expressions and development of physical qualities. It consists in two groups:

1- Methods used in the learning of movement expressions which are generally used for the low cycle classes and follow-up classes

2- Methods for the development of physical qualities which are mostly used for the high classes because they are familiar with these exercises and the manner they are performed. However work is focused in improving the quality of the exercise.

Therefore, from the very beginning the students become aware of the movements through demonstrations, as the easiest way to be perceived by the student (mainly from Grade 1-4), then explanation of the exercise which takes less time from the teacher and more time from the student (used mainly for Grade 1-6), because it is assumed that up to these grades, the student has appropriate knowledge in most of the topics and their content. It is important to emphasise that the combination of the first two methods i. e explanation of the new topic and its demonstration. On the contrary, the acquisition of such skills through the frequent and systematic exercise is mostly used for the grades 7-9.

\section{Result}

From the study we have conducted in all the 9-year schools in Tirana, we have concluded in the following data which are reflected in the table and the respective graphs for each methods are herewith below based on the general data of the table. During the physical education classes, starting from the pre-school system to the eights grade the student must perceive and understand easily the topic of the class if the teacher will make use of the demonstration method, because the student of such grades initially becomes informed of all the movement activities. The effect of use of this method is clearly evident from the use of data which we have presented in the following table.

General table

\begin{tabular}{|l|c|c|c|c|c|c|c|c|c|c|}
\hline Grade / Methods & Pre-school system & I & II & III & IV & V & VI & VII & VIII & IX \\
\hline Demonstration method & $99.90 \%$ & $95 \%$ & $93 \%$ & $90 \%$ & $50 \%$ & $47 \%$ & $35 \%$ & $15 \%$ & $10 \%$ & $10 \%$ \\
\hline Verbal method & & $5 \%$ & $7 \%$ & $10 \%$ & $50 \%$ & $53 \%$ & $50 \%$ & $40 \%$ & $15 \%$ & $10 \%$ \\
\hline Exercise method & & & & & & & $15 \%$ & $45 \%$ & $75 \%$ & $80 \%$ \\
\hline
\end{tabular}

\begin{tabular}{|c|c|}
\multicolumn{2}{c}{ Specific tables and graphs } \\
\begin{tabular}{|c|c|}
\hline & Demonstration method \\
\hline S/P-IV & $85.58 \%$ \\
\hline $\mathrm{KI} / \mathrm{V}-\mathrm{VI}$ & $41 \%$ \\
\hline $\mathrm{KI} / \mathrm{VII}-\mathrm{IX}$ & $11.66 \%$ \\
\hline
\end{tabular}
\end{tabular}




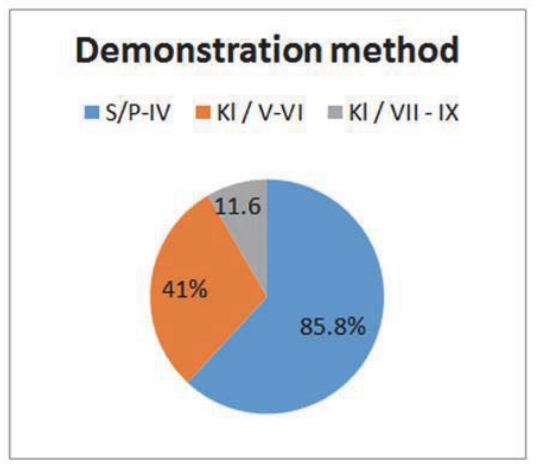

The verbal or explanation method of exercise takes less time from the teacher and more time from the student, thus giving priority to the development of skills of the students. It may be used for the Grades 4-6 because it is assumed that up to these grades, the student has appropriate knowledge in most of the topics and their content. It is important to emphasise that the combination of the first two methods i. e explanation of the new topic and its demonstration.

\begin{tabular}{|c|c|}
\hline & Verbal method (explanation) \\
\hline $\mathrm{S} / \mathrm{P}-\mathrm{IV}$ & $17.50 \%$ \\
$\mathrm{KI} / \mathrm{V}-\mathrm{VI}$ & $52 \%$ \\
\hline $\mathrm{KI} / \mathrm{VII}-\mathrm{IX}$ & $21.60 \%$ \\
\hline
\end{tabular}

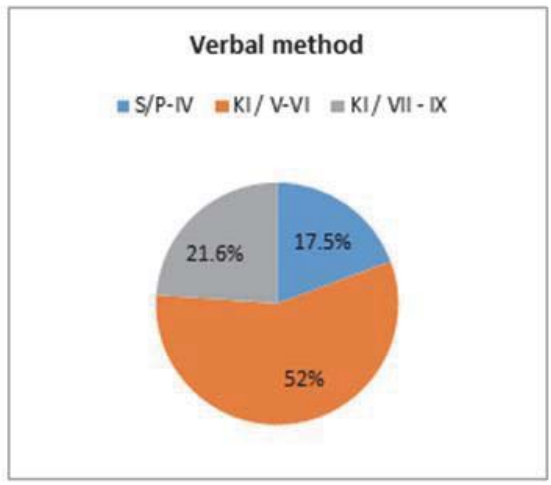

The teaching classes from the seventh to the ninth grade is more active because as a result of a better performance in the lowest grades, the student may be instructed by the teacher and apply them through a repetition of exercise, several times more, and consequently, the movement skills in all the disciplines which the teaching programme contains, are improved

\begin{tabular}{|c|c|}
\hline & Verbal method (explanation) \\
\hline $\mathrm{S} / \mathrm{P}-\mathrm{IV}$ & $17.50 \%$ \\
\hline $\mathrm{KI} / \mathrm{V}-\mathrm{VI}$ & $52 \%$ \\
\hline $\mathrm{KI} / \mathrm{VII}-\mathrm{IX}$ & $21.60 \%$ \\
\hline
\end{tabular}




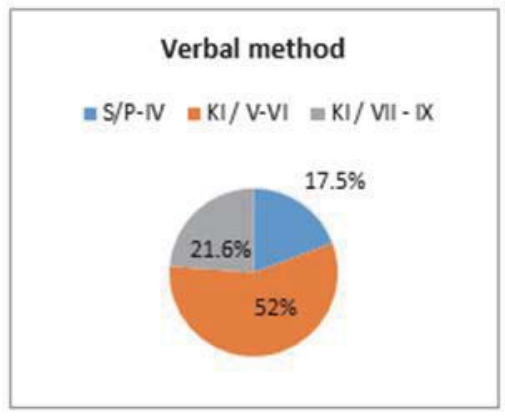

The teaching classes from the seventh to the ninth grade is more active because as a result of a better performance in the lowest grades, the student may be instructed by the teacher and apply them through a repetition of exercise, several times more, and consequently, the movement skills in all the disciplines which the teaching programme contains, are improved.

\begin{tabular}{|c|c|}
\hline & Exercise methods \\
\hline S/P-IV & $0.00 \%$ \\
\hline $\mathrm{Gr} / \mathrm{V}-\mathrm{VI}$ & $8 \%$ \\
\hline $\mathrm{Gr} / \mathrm{VII}-\mathrm{IX}$ & $66.66 \%$ \\
\hline
\end{tabular}

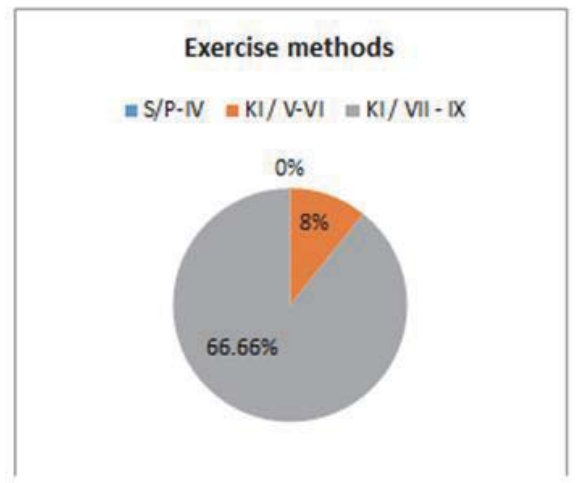

\section{Conclusion}

The forms of physical education which are applied by the physical education teacher in the 9-year schools are of special importance because they help in organising as productive as possible teaching classes and attaining the aimed objectives which are closely linked to the improvement of the health of the students and their physical preparation. Therefore, such classes must be organised and delivered in a planned way, fully in line with the purposes of the teaching class and the particularities of the age of the students.

\section{References}

Prof. DR Jani Daci. Didactic of physical education (pg 10) (2004)

Wlodkowsli, R. Washington DC. Motivation and teaching

Stavri LLambriri, "Education Development" Association supported by UNICEF. Minimum necessary objectives of the student (2007)

Cratty, B, J. Intelligence in Action. Englewood Cliffs ,NJ : Prentice-Hall (1973)

Rovena Elmazi. Leasure and Recreation Sport. jurnal of Physicol Activity and Sports volume 2 issue 1 August 2014

Cratty , B,J.Perceptual and Motor Development in Infans and children. New York : Collier-

MacMillan Co. (1970)

Angela Glenn, advisory teacher at Medway ICSS 
Jacquie Cousins, manager at the referral unit of elementary pupils

Gallahue , D. L. Understanding Motor Development in children. New York : John Wiley and Sons (1982)

Volumes: Play and learning in early years / Eliminating barriers to learning in early years Terry F Pettijon : Ohio State University

Gerhardt, L. A . Moving and Knowing : The Young Child Orients Himself to Space. Englewood Cliffs, NJ: Prentice-Hall (1973) 